\title{
Report on Open Science Meeting and Panel Discussion
}

The first PAGES Open Science Meeting 'Past Global Changes and their Significance for the Future', jointly organised by PAGES and the Environmental Changes Research Centre (ECRC), University College London, was held in the University of London Senate House, April 20 -23, 1998. The oral presentations took the form of overviews by distinguished invited speakers whose remit was to present the stateof-the-art in all the main aspects of past global change research within the context of IGBP. In addition, over 200 posters were displayed. The published output from the meeting includes a 140 page volume of Abstracts (containing over 350 items) available from the PAGES Project Office and also via the PAGES web site (http:/ /www.pages.unibe.ch/). A double special issue of the Quaternary Science Reviews, containing review papers by each of the invited speakers will be published in 1999 and will also be available in book form. It is hoped to distribute a CD-ROM of the PAGES Data Base along with this volume.

The meeting culminated in a panel discussion chaired by Professor Chris Rapley, Director of the British Antarctic Survey and former Executive Director of the International Geosphere-Biosphere Programme (IGBP). Members of the panel were Sir John Houghton, co-chairman of the Science Assessment Working Group of the Intergovernmental Panel on Climate Change (IPCC), Professor Hartmut Grassl, Director of the Joint Planning Staff for the World Climate Research Programme (WCRP), Bill Hare, Climate Policy Director of Greenpeace International, Ray Bradley, Professor of Climatology at the University of Massachusetts and Chair of the PAGES Scientific Steering Committee (SSC) and Jonathan Overpeck, Head of the US NOAA Paleoclimatology Program, Director of the World Data Center-A for Paleoclimatology and member of the PAGES SSC.

The Abstract Volume of the London Open Science Meeting contains the abstracts of 27 plenary lectures and 330 posters. Copies are available from the IPO, so feel free to order by fax, letter or e-mail or using the order form on our website: http:// www.pages.unibe.ch/Publications/ publications.html
The key aims of the panel discussion were to link the research agenda of PAGES, as outlined in the presentations and its recently published 'Status Report and Implementation Plan' as effectively as possible to the concerns of all those dealing with the prediction and management of future global changes and their impacts on human society. The panel members from outside PAGES made introductory statements to open the discussion.

Sir John Houghton stressed the essential role of PAGES science in:

- validating climate and other earth system models.

- increasing the quantitative understanding of climate sensitivity to different forcings.

- improving parameterisation of key earth system processes involved in climate change, for example biosphere feedbacks.

- characterising climate regimes in time and space and documenting their role in the pattern of variability at regional level.

- highlighting the importance of rapid change and of the feedbacks and non-linear processes involved.

- detailing the impacts of climate variability on other environmental systems and especially on human activities by presenting a paleo-perspective on human adaptability and on the problems involved in planning for sustainability in a future dominated by change.

Professor Grassl stressed the links between PAGES and WCRP mainly through the CLIVAR (Climate Variability and Predictability) Study. Inputs to CLIVAR from the PAGES research community should lead to an extension of the instrumental record to the whole of the last millennium through use of quantitatively calibrated proxies that achieve precise and accurate age control, annual resolution and global significance. Tree rings, varved (annually laminated) sediments, ice cores, corals and speleothems all provide this potential, as do documentary records. Grassl stressed the need for collaborative work between modellers and data researchers on the development of realistic and well validated transient models of non-linear climate change. He also emphasised the crucial role of isotope studies in global change research, stressing the need to strengthen the Global Network for Isotopes in Precipitation (GNIP) and to promote both the PAGES 'Isotope Mapping' (ISOMAP) programme and the newly established 'Isotopes in the Hydrological Cycle' (ISOHYC) initiative as complementary developments of great potential.

Bill Hare emphasised the role paleo-research must play by using the information at its disposal to identify critical environmental thresholds for rapid non-linear change and to establish the ways in which these may be influenced by different rates of forcing. In the policy-related domain, he stressed the need to understand better past natural variability and, in particular, the incidence and impacts of extreme events - a matter of major concern in risk assessment. By improving our understanding of the role of the terrestrial biosphere in past climate change, PAGES should also contribute to evaluating the potential for policy makers meeting their obligations within the Climate Convention by increasing biomass rather than reducing carbon emissions. Hare also pointed up the urgent need to use paleo-records more effectively in documenting the interlinked past variations in global ice-volume, sea-level and coastal change, so that future changes can be more effectively predicated and accommodated in policy development.

In concluding the introductory statements and inviting contributions from the floor, Chris Rapley asked to what extent and in which ways could the paleo-record contribute to our understanding of a forcing so unique and unprecedented as that currently operating.

continued on bottom of page 12

\section{Winners of the Poster Competition for Young Scientists from Developing Countries}

sponsored by Environmental Change Research Centre, University College London

\begin{abstract}
Maria Martha Bianchi (Argentina)
Tracing fluctuations in the strength of Westerlies at $41^{\circ} \mathrm{S}$ using Late Glacial - Holocene pollen records from North Western Patagonia

Vladimir O. Elias (Brazil)

A chemical tracer for the reconstruction of forest fires in the Amazonas environment and geological record
\end{abstract}

Rashit Hantemirov (Russia)

A 5,000 year larch tree-ring record from the north of West-Siberian Plain and its applications to palaeoclimatic studies
Nejib Kallel (Tunisia)

Mediterranian pluvial periods and sapropel formation during the last 200,000 years

A.K. Singhvi (India)

Synthesis of luminescence chronology of loess accumulation episodes and implications for global land-sea correlation

Jule Xiao (China)

East Asian monsoon variation during the last 130,000 years: Evidence from the Loess Plateau of China and Lake Biwa of Japan 


\section{PAGES Focus 3: A new Initiative on past Human Impacts}

The main thrust of the PAGES program hitherto has been towards a better understanding of past climate change and its implications for the future. Focus 3 , which is concerned with the past impact of human activity on ecological and hydrological systems, has never been fully articulated, though significant progress has been made in one specific area - human impact on fluvial systems- thanks to the efforts of Bob Wasson. At the recent PAGES SSC meeting, held in Pallanza, N. Italy, June 19-21, an overall strategy was presented and endorsed. This strategy envisages seven interlinked themes as set out below. Their coordination and their articulation as PAGES Activities and Tasks will be the responsibility of a small steering group soon to be identified. The goals of the paleoscientists involved in this exercise will include the following:

- To define, promote and pursue areas of shared interest between PAGES and other IGBP project elements.

- To contribute fully to the PAGES, and eventually IGBP, syntheses currently being undertaken

- To push the development of these themes soundly forward toward and during the next stage of IGBP's work from the year 2000 onwards.

The themes briefly noted below have yet to be fully defined and, in some cases, leaders have yet to be identified. A work- shop to develop science and implementation plans will be held in late 98 / early 99 Meanwhile, colleagues interested in contributing to this aspect of PAGES work are invited to contact the IPO and its Executive Director (oldfield@pages.unibe.ch) who will be responsible for the overall coordination of Focus 3 in its early stages.

\section{Seven themes}

The themes envisaged at this stage are as follows:

\section{The history of greenhouse gas exchanges between the terrestrial biosphere and atmosphere}

These exchanges are of major concern in relation to understanding present day and future carbon dioxide and methane fluxes and budgets. There is an urgent need to improve our insight into the way past changes in land cover and hydrology have affected the fluxes and reservoirs over the non-marine part of the biosphere. The task spans a range of themes, from the past carbon balance in wetlands, to the impact of both deforestation and reforestation on $\mathrm{CO}_{2}$ fluxes at both regional and global scales. Moreover, there is a strong case for broadening it to include a concern with nitrogen species. One major advantage of undertaking this task for the past lies in the way in which it can be linked, on a range of timescales, to the trace gas record in ice cores. The task is seen as contributing to the GAIM led 'paleo-trace-gas challenge' and as helping to forge links between PAGES and other IGBP Project Elements, especially GCTE, BAHC and IGAC.

\section{Past biogeochemical fluxes within fluvial systems}

This theme is closely linked to the next two and it embraces the concerns of the BLOP report (Modelling the Transport and Transformation of Terrestrial Materials to Freshwater and Coastal Ecosystems) as well as one of the main tasks for PAGES within the IGBP inter project initiative on 'Continental Aquatic Systems'. It is also currently being actively promoted by the LUCIFS project (Land Use and Climate Impacts on Fluvial Systems during the Period of Agriculture) led by Bob Wasson. Further information on this project is contained in an article in this Newsletter on page 14 .

\section{The historical context of multiple threats to both aquatic and terrestrial ecosystems}

Climate variability and future climate change are only one factor, and perhaps often not the most important factor, in the complex of threats facing both terrestrial and aquatic ecosystems. Studies of soil erosion, surface

Open Science Meeting, continued from page 11

A wide-ranging discussion followed in which the issues raised included:

- lack of opportunities for developing and funding effective links between the areas of environmental and social sciences whose collaboration is essential to the emerging global change research agenda.

- the need, in an increasingly data-rich research environment, to focus on critical time intervals and processes.

- a request to IPCC for a clearer identification of the burning, unresolved questions to which paleo-research should make a crucial contribution. Suki Manabe, drawing up his own list, suggested the following:

- can we solve the problem of the 'missing carbon sink' through a concerted attack using the stable isotopes of carbon to better characterise the sinks, sources and fluxes?

- will global warming really reduce surface salinity in the North Atlantic?

- which are the key aerosols in climate feedback and what are their effects? - what are the most important observa- tional activities required to develop and validate models?

- the need for present day calibration to be linked to paleo-research projects. This may be one of the ways in which, given adequate coordination, essential monitoring programmes can be sustained.

- the challenge of incorporating hypothesis testing in the present research agenda, for example to test the possible role of marine biota in climate forcing.

- the urgent need, in some parts of the world, for more AMS radiocarbon measurement facilities worldwide, both for dating and for developing further the 'tracer' role of radiocarbon.

- the strong desirability of broadening the PAGES research agenda to encompass more fully other aspects of past global change than climate.

- the need to increase awareness of the relative magnitudes of changes in large scale averages. For example, the 'Little Ice Age' had major impacts, yet, over the northern hemisphere as a whole, appears to have been only 0.5 to $1^{\circ} \mathrm{C}$ cooler than the last few decades. In contrast, the IPCC worst case envisages a rapid warming of up to $4^{\circ} \mathrm{C}$.

The leading points made by the panel members and the ensuing discussion provided ample justification for regarding PAGES research as a vital contribution to understanding future environmental change and its human implications. They also provided many pointers to the ways in which the existing research agenda can be shaped in order to increase its impact and relevance. Our central task is to use the record from the past to shed light on what predicted future changes will actually mean for a still rapidly growing world population for which the goals of sustainable development and the realities of environmental change will be intimately linked.

\section{Frank Oldfield}

Executive Director, PAGES IPO

oldfield@pages.unibe.ch 